\title{
Internet Supervision and Parenting in the Digital Age: The Case of Shanghai
}

\author{
Yu Cheung Wong ${ }^{*}$, , Kit Mui Ho ${ }^{1}$ and Honglin Chen ${ }^{2}$ \\ ${ }^{I}$ The Chinese University of Hong Kong, Hong Kong \\ ${ }^{2}$ Fudan University, Shanghai, China
}

\begin{abstract}
This research paper explored the issue of parenting confidence in internet supervision in Shanghai. It examined the methods used by Shanghai parents in supervising children's Internet use, the confidence of parents in helping children to benefit from the Internet and protect them from possible threats, and the factors affecting parents' confidence in their parenting practices. Data were collected from a household survey with a representative sample of 796 low-income families and 799 non-low-income families. Post-stratified weighting was applied to obtain representation of families with children aged 9-17 in Shanghai. Our findings show that Shanghai parents used restriction most frequently in internet supervision. More than one-fifth of parents had limited confidence in helping their children benefit from the Internet and one-eighth in protecting their children from possible Internet threats. Multiple regression models show that better Internet knowledge, an authoritative parenting style, more involvement in children's online activities and a positive attitude towards the Internet are factors which were associated with higher parenting confidence in internet supervision. Findings suggest that efforts in assisting parents review their attitude towards the Internet and learn new supervision methods are important, especially for parents on the lower socio-economic strata.
\end{abstract}

Keywords: Internet risks, internet supervision, parent-child relationship, parenting confidence, parenting styles, Shanghai.

\section{INTRODUCTION}

It is the developmental nature of young people to experiment and explore new things. The internet technology offers them a modern and convenient way to explore the world virtually without boundaries. It also becomes a source of conflicts between young people and their parents in this era. In the past two decades with the rise of the Internet, free web surfing, social networking, instant messaging and online shopping all become growing concerns to parents. The more recent smart phone and "apps" application add even more challenges. Why? Parents are generally not familiar with the new technology that only appears recently. The Internet is like a two-edged sword. It can do great help to youngsters as much as it can bring along harmful and undesirable effects such as identity theft, cyberbullying, and exposing to sexually explicit materials. Many parents worry their children will get addicted to the Internet, but they also know it helps their children acquire knowledge. It is extremely hard for parents to find the balance and this impacts greatly on the parent-child relationship. Parents begin to lose confidence in their parenting and do not know what the best way is to handle their children's internet behaviors.

Shanghai is a fast developing city with a comparatively higher internet penetration rate in China [1]. Parents in Shanghai should be facing similar difficulties. How are they going to tackle this parenting issue? Research data in this

*Address correspondence to this author at the Department of Social Work, The Chinese University of Hong Kong, Shatin, N.T., Hong Kong;

Tel: (852)3943-7495; E-mail: ycwong@swk.cuhk.edu.hk area are still lacking. The present study intends to fill this gap and explore how parents in Shanghai supervise their children's use of the Internet. Specifically, this research paper will provide an investigation of (1) the methods parents use in supervising their children's internet activities; (2) the confidence of parents in helping their children to benefit from the Internet and protect them from possible threats; and (3) the factors affecting parents' confidence in their parenting practices.

\section{LITERATURE REVIEW}

Parents have been increasingly sensitive to threats in children's Internet use, like possible addiction to Internet games and social networking websites. In fact, recent reports in internet threats, such as revealing family or personal information, sexual solicitation from Internet contacts, identity theft, cyber-bullying and online child abuse, are making parents even more conscious on how they should better supervise their children in the use of the Interne $[2,3]$.

\section{Parental Supervision of Children's Internet Use}

The parental responsibility in supervising children's use of the Internet is a new-found challenge in the information age. Most parents, though recognizing the positive use of the Internet for their children's education, believe that children would not benefit much if appropriate guidance is not provided. Some parents worry that the Internet might become the biggest threat to their children after TV [4]. Others worry about the lack of diversity in their children's leisure activity and some also fear that their children become 
passively attached to the Internet $[5,6]$. Parents therefore use various means to manage their children's use of the Internet.

Research finds that most parents would discipline children's online behavior and communicate with their children to establish norms and rules [7]. One of the methods frequently used by the parents is to limit the amount of time that their children can surf the Internet [8]. In addition, they may also try to limit the contents that their children can browse by installing filtering software, regularly checking the browsing history, insisting on their own presence when their children are using the Internet, co-surfing with their children, and even controlling the power supply and/or the Internet connection [7-14]. Besides all these, some of the parents may also restrict the Internet activities of their children. For example, when online games and educational sites are generally permitted, most of the parents will prohibit their children to go out with online friends, and going to the Internet café [7], or stop them when they are talking to or approached by strangers in instant messaging [14]. Research shows "a positive impact when parents surf together with their children on the Internet, discuss with them and recommend specific websites. Nonetheless this is only observed in about one third of parents" [15].

It can be seen that rule setting, restriction, close monitoring and involving in children's internet activities are the major categories of supervision methods adopted by parents. This framework also serves as the backbone of the present study in exploring parents' supervision behaviors.

\section{Internet Parenting Styles}

Based on Baumrind's framework of parenting styles along the dimensions of parent control and parent responsiveness, four broad categories of parenting styles were defined:

- "Authoritative parenting has high levels of demand, warmth, and psychological autonomy;

- Authoritarian parenting is characterized by high levels of demand but low levels of warmth and psychological autonomy;

- $\quad$ Permissive parenting is characterized by low levels of demand and relatively high levels of responsiveness;

- $\quad$ Neglectful or laissez-faire parenting is characterized by low levels of demands and low levels of responsiveness" [16].

Applying these four parenting styles in internet parenting, a recent study [14] found that the authoritative Internet parenting style is the most dominant type being adopted. Parents require their children to establish responsible Internet usage and behaviors by setting and discussing the rules with them. The second most frequently used Internet parenting style is the permissive style where parents are not setting any rules and restrictions for the children and avoiding any confrontations at the same time. However, they will show encouragement and care when it is needed. On the contrary, defining strict rules and boundaries for their children to obey but never explaining or talking about these rules of surfing the Internet with their children are common strategies adopted by parents with authoritarian style. This style is less popular among parents than the previous ones. The least popular type of style among the parents is the laissez-faire Internet parenting style. Parents simply pay no attention to their children's use of the Internet. They will not set rules to restrict their children and at the same time, will not show any support or provide any guidance to their children $[7,14]$

\section{Culture and Parenting}

Western cultures in general view authoritative parenting more conducive to child development. Research suggested that children nurtured by authoritative parenting style tend to develop higher self-esteem, better academic achievement, lower depression and lower anxiety [17-22]. On the contrary, authoritarian parents influence children's self-esteem and academic result adversely [18, 21, 23]. Under authoritarian parenting, children also tend to use maladaptive achievement strategies such as "failure expectations", "task-irrelevant behaviour" and "passivity" [24]. The influences of permissive parenting are inconsistent $[18,21,25]$.

However, what is seen as optimal parenting may vary depending on culture. The cultural differences between Western and Asian parenting practices are rather substantial. Asian parents prefer authoritarian parenting as they generally believe that this will have a positive influence on children's behaviours, socialization and academic results [22, 23]. Moreover, results of studies using Asian subjects were not compatible with those using Western subjects [22]. Authoritarian parenting was found to have positive impact on children's academic achievement, whereas authoritative parenting was not [23]. Some other studies had diversified conclusion on the benefits and harms of different parenting styles [25-27].

\section{Parenting Confidence}

Interest in the measurement of parenting confidence has grown in recent decades, mainly in the area of health care. While different terms like perceived parenting self-efficacy and sense of competence have been used within the literature, broadly speaking all pertain to parental feelings of competence in the parenting role [28]. In the present study, the term parenting confidence has been employed to reflect parents' subjective experience.

An increasing number of studies over the past 20 years have highlighted that these parenting-confidence perceptions represent key elements of parents' subjective experience and act as important resiliency or protective factors [29]. Research shows that high parenting-confidence can mitigate parental depression, stress and relationship difficulties, and is associated with actual parenting competence and positive child outcomes [28-30].

Research on parenting confidence in internet supervision is rare. The present study will pioneer in this direction to explore the factors that affect parenting confidence. The major hypotheses that this study wants to test are that levels of parenting confidence in helping children to "benefit from the use of the Internet" and "protect children from possible threats" are associated with parents' and children's profiles, parenting style and supervision methods, attitudes of parents towards the Internet, parent-child relationship and family atmosphere in general. 


\section{METHODOLOGY}

\section{Target Population}

This study project targeted children aged between 9 and 17 and their parents in Shanghai. Two representative samples were collected in Shanghai during the study. One of the samples was collected among the low-income families with children at the targeted age. Around eight hundred families were enumerated. Another sample was collected among the non-low-income families; a similar number of them were interviewed. This allows us to compare the differences between the two types of families.

\section{Sampling Procedure}

The study adopted a household-based, multistage sampling method. There were altogether seven districts in the urban centre of Shanghai and another eight districts located in the countryside at the time of study. The sampling procedure consisted of three stages. The first one selected the districts both in the urban centre and countryside. Two street-offices ${ }^{1}$ in each district were further selected and then followed by several resident committees in each street office. Resident committees are "self-governed" grass-root organizations. They have the responsibility to implement programmes instructed by various government departments via the street offices they belong to. They also keep a list of residents within their respective service boundary. Special attentions were paid to those who receive government benefits and allowances.

The second stage sampling was conducted with the help of these selected resident committees. Eight hundred households with children at the targeted age among the nonlow-income households were randomly selected from the resident lists kept by the resident committees. This formed the non-low income sample.

In addition, in each resident committee, all the households receiving social assistance benefits $\left(\right.$ dibao $\left.^{2}\right)$ and had children at the targeted age were selected into the lowincome sample. Additional low-income households were randomly selected with the help of the resident committees. Altogether, the number of these selected low-income households (together with those on social assistance) was also around 800 . Both the low-income and non-low-income households were visited and further screened.

Stage three sampling was conducted within each selected household. The child ${ }^{3}$ at the targeted age in each household was interviewed. In addition, the parent who took up the major responsibility in taking care of the child, especially in supervising the use of Internet, was also invited to complete the questionnaire. Random selection was applied if both parents indicated that they were equally responsible in taking care of the child. Two separate sets of questionnaires were

\footnotetext{
${ }^{1}$ Street offices are government out-posts in areas of around 100,000 persons. ${ }^{2}$ The Chinese term for the social assistance program in China, officially known as the Minimum Living Standard Guarantee or MLSG programme ${ }^{3}$ Mainland China started implementing the One-child Policy in late 1970s, and the Policy was only relaxed in 2014. At a result, an ordinary family would have one child at the targeted age only. Before the relaxation, parents giving birth to an extra baby would have to pay a heavy penalty, which amounted to about 2-6 times of the annual salary of both parents.
}

designed respectively for children and parents. Face-to-face interviews were conducted with trained interviewers.

At the completion of data collection, 796 low-income families were enumerated while 799 non-low-income families were also interviewed. The overall sample of 1,595 was over-represented by low-income families. Post-stratified weighting was applied in analyzing the data. The weighted sample reflected the proportion of household with children aged between 9 and 17 in districts located in the urban centre and countryside as well as the proportion of non-low-income households and low-income households with children at the targeted age. It also resembled the proportion of households with children at the targeted age on social assistance in Shanghai.

\section{Instruments}

The content and structure of the questionnaires for parents and children were similar. They both contained sections on personal background such as personal information and socio-economic status, digital profile regarding accessibility, knowledge of Internet and its usage, attitudes towards the Internet, internet supervision, parenting styles, satisfaction about family life, etc. For the parent questionnaire, specific questions on their confidence in internet supervision were included. The present paper will focus on exploring the parents' perception only.

\section{Confidence in Supervising Children's Use of the Internet}

The major dependent variables of the study were two global questions regarding parents' confidence in (i) "helping their children benefit from the use of the Internet", and (ii) "protecting children from possible Internet threats". As the study wants to measure the subjective experience of parents, their perceived parenting confidence was asked on a 5 -point Likert-type scale ranging from 1"not confident at all" to 5 "highly confident".

\section{Methods of Supervising and Guiding Children's Use of the Internet}

The scale of methods in parents supervising their children's use of the Internet was constructed by Wong [31] in his study on cyber-parenting in Hong Kong. A total of 17 methods were identified and included in the present scale with modifications of terminology to suit the internet use in mainland China. They were:

a) "regularly discussing their children's online experiences with them,"

b) "discussing the threats posed by Internet usage with them,"

c) "encouraging them to find constructive uses for the computer and Internet,"

d) "joining them in their online activities (e.g. watching movies, playing games, exploring common interests, MSN, etc.,"

e) "sharing computer knowledge/ skills together,"

f) "becoming a weixin or $Q Q$ friend of their child," 
g) "reminding them when they have used the computer for too long or too late,"

h) "restricting use if school performance deteriorates,"

i) "restricting the amount of time they use the Internet,"

j) "setting rules about interacting with strangers,"

k) "installing software to filter access to undesirable websites or to monitor children's online activity,"

1) "setting rules about which websites can be visited,"

m) "setting rules about downloading and uploading material,"

n) "setting rules about the disclosure of personal information,"

o) "monitoring the web activities and online communication of children (e.g. check browsing history, $Q Q$ friends),"

p) "disconnecting the power supply/ LAN connection when necessary," and

q) "sending them to programs organized by a youth group or other trusted organization about how to use the Internet sensibly."

Questions on these items were on a 5-point scale ranging from "never" to "always".

\section{Parenting Style}

A 32-item parenting style questionnaire, which was developed by McKay [32] based on the work of Robinson et al. [33], was used in this study. These items were originally used to assess authoritative, authoritarian, and permissive parenting styles based on Baumrind's classification for older children. The items were translated into Chinese and back translated to English to check translation accuracy. These items were also modified to be include culturally sensitive and to cater for younger children in this study. For example, one original item "I punish by taking privileges (e.g., use of car, rent) away from our child" was changed to (e.g. watching $\mathrm{TV}$ and playing outside). Items were measured with a 5-point scale ranging between 1 "never" to 5 "always". According to McKay's study, Principal Component Extraction and varimax rotation yielded three factors of Authoritative, Authoritarian and Permissive styles with good eigenvalue and reliability scores [32].

\section{Parent-Child and Family Relationship}

Six global questions about their satisfaction with different aspects of parent-child/ family relationships were asked on a 5-point Likert-type scale:
a) "time spent with your children,"
b) "parent-child relationship,"
c) "time spent with family members,"
d) "family atmosphere,"
e) "communication among family members," and
f) "family cohesion."

The responses ranged from 1 "very dissatisfied" to 5 "very satisfied".

\section{Attitudes Towards the Internet}

Six questions were asked to gauge parents' attitudes towards the Internet, including

a) "The Internet is indispensable in modern life,"

b) "Incapacity to use the Internet will lead to disconnection from society,"

c) "The Internet helps learning new things,"

d) "It is easy to obtain information from the Internet,"

e) "It is easy to get indulged in the use of the Internet," and

f) "The Internet is filled with undesirable information."

The responses were also located on a 5-point Likert scale ranging between 1 "strongly disagree" to 5 "strongly agree".

\section{FINDINGS}

\section{Parents' Profile}

Among the 1,595 households interviewed, 1,482 (92.9\%) had only one child aged between 9 and 17, reflecting the one-child policy in mainland China. More than half (54.9\%) of the parents in our sample were female. Regarding education level, around one-third (31.5\%) had only junior secondary education or below. The percentage was similar between males $(32.9 \%)$ and females $(30.4 \%)$. About $12 \%$ and $10 \%$ of fathers and mothers respectively in our sample had never used a computer. The percentage never having used a computer among those with junior secondary or less schooling was much higher $(21.7 \%)$ compared to $5.5 \%$ among those with senior secondary or above. Of all parents interviewed, $16.4 \%$ expressed that they had no knowledge of the Internet. Among those with junior education level or below, $37.8 \%$ indicated they had no knowledge of the Internet; while the percentage is $6.5 \%$ with senior secondary or above.

\section{Computer Access and Usage}

Nearly all $(94.9 \%)$ of the 1,595 families in our sample had a computer at home. Among these 1,513 households, $97.5 \%$ had an Internet connection via their home computer Most parents (71.1\%) regarded their children's time in using the Internet was just right. More parents (17.1\%) of children aged 9-13 considered that their children spent much/ too much time using the Internet, while the percentage (10.2\%) was much lower for those with children aged 14-17.

\section{Methods of Supervising and Guiding Children in Using the Internet}

Table 1 shows the mean values and standard deviations of various methods used by parents to supervise and guide their children in using the Internet. The scores ranged from 1 "Never/rarely" to 5 "Always". The methods with highest mean values were "Remind them when they have used it for too long 
Table 1. Methods used to supervise and guide children's use of the internet.

\begin{tabular}{|c|c|c|c|}
\hline Methods Used & Mean & $S D$ & Valid Cases \\
\hline a) Regularly discuss their online experience with them & 2.17 & 0.862 & 1595 \\
\hline b) Discuss the threats of Internet usage with them & 2.57 & 0.951 & 1595 \\
\hline c) Encourage them to find good uses for the computer and Internet & 2.37 & 0.923 & 1595 \\
\hline d) Join them in their online activities & 2.32 & 0.953 & 1595 \\
\hline e) Share computer knowledge/ skills together. & 2.42 & 0.933 & 1595 \\
\hline f) Become a weixin or $Q Q$ friend of my child & 2.24 & 1.149 & 1595 \\
\hline g) Remind them when they have used it for too long or too late. & 3.68 & 1.102 & 1595 \\
\hline h) Restrict their use if the school performance deteriorates. & 3.32 & 1.094 & 1595 \\
\hline i) Restrict the amount of time they use the Internet. & 3.32 & 1.118 & 1595 \\
\hline j) Set rules about interacting with strangers & 3.15 & 1.258 & 1595 \\
\hline k) Install software to filter access to undesirable websites or to monitor children's online activity. & 2.37 & 1.406 & 1595 \\
\hline 1) Set rules about which websites can be visited. & 2.43 & 1.293 & 1595 \\
\hline m) Set rules about downloading and uploading material. & 2.40 & 1.241 & 1595 \\
\hline n) Set rules about disclosure of personal information. & 2.72 & 1.300 & 1595 \\
\hline o) Monitor the web activities and online communication of children. & 2.14 & 1.132 & 1595 \\
\hline p) Unplug the power supply/ LAN connection when necessary. & 1.93 & 0.991 & 1595 \\
\hline q) Send them to programs organized by a youth group or similar organization about how to use the Internet sensibly. & 2.41 & 1.173 & 1595 \\
\hline
\end{tabular}

Range of scores: $1-5,1=$ Never/rarely, $5=$ Always.

or too late" (Mean=3.68), and "Restrict their use if the school performance deteriorates" (Mean=3.32) and "Restrict the amount of time they use the Internet" (Mean=3.32). The methods least used were "Monitor the web activities and online communication of children" (Mean=2.14) and "Unplug the power supply/ LAN connection when necessary" (Mean=1.93).

From the 17 methods used by parents, Principal Component Extraction yielded three factors with eigenvalues larger than 1.0 $(6.20,2.20$ and 1.50). Varimax rotation generated 3 orthogonal factors with satisfactory reliability scores (Table 2). After examining the pertinent items in each factor, the three factors were given the title of "Involvement", "Restriction" and "Close Monitoring".

\section{Parenting Styles}

Initial Principal Component Extraction yielded seven factors, each with an eigenvalue larger than 1 . Rotated factor matrix generated four factors and Table 3 shows these factors and the reliability scores of the pertinent items. The results were very similar to those of the Hong Kong parents in Wong's study [31]. They are the authoritative, permissive, authoritarian (irritable) and authoritarian (controlling) parenting styles. The authoritarian (irritable) parenting style relates more to the emotional expression and punitive measures when they disapprove children's behaviors. Items such as "I yell or shout when I disapprove of our child's actions or choices" and "I punish by taking privileges (e.g. watching TV, and playing outside) away from our child" were loaded into this factor. The authoritarian (controlling) parenting style refers to the attempt of parents to assert parental power, and their attempts to control their children's behavior. Items such as "I remind our child of all I have done for him/her" and "I always try to change how our child feels or thinks about things" were associated with this substyle.

\section{Parent-Child/Family Relationship}

Table 4 presents the satisfaction levels of the parents towards various aspects of the parent-child and family relationships. The parents reported very high levels of satisfaction towards all six aspects in the questionnaire. The satisfaction level was higher in parent-child relationship ( $94.5 \%$ indicated being satisfied or very satisfied), family cohesion (93.4\%) and family atmosphere (93.0\%). Comparatively, the satisfaction level was lower in the amount of time spent with children $(84.4 \%)$, and time spent with family members $(84.5 \%)$. Mothers were observed to report a higher level of satisfaction than fathers in all six aspects, and those with higher education level also reported higher levels of satisfaction.

\section{Confidence of Parents in Supervising their Children's Use of the Internet}

The percentage of parents feeling confident and highly confident in helping their children benefit from the Internet was $42.4 \%(45.4 \%$ for parents with children aged 9-13, $37.5 \%$ for $14-17$ ). About $8 \%$ of parents expressed that they were not confident at all. The confidence of parents in protecting their children from possible Internet threats was comparatively higher. More than half (53.6\%) of the parents responded that they were confident or highly confident (58.2\% for parents with children aged $9-13,46.0 \%$ for 14 - 
Table 2. Factors of methods used to supervise and guide children.

\begin{tabular}{|c|c|}
\hline Factors and Items & Rotated Factor Loadings \\
\hline \multicolumn{2}{|l|}{ Involvement (Cronbach's $\alpha: 0.840)$} \\
\hline b Discuss the threats of Internet usage with them & 0.616 \\
\hline c Encourage them to find good uses for the computer and Internet & 0.760 \\
\hline e Share computer knowledge/ skills together. & 0.779 \\
\hline f Become a weixin or $Q Q$ friend of my child & 0.677 \\
\hline \multicolumn{2}{|l|}{ Restriction (Cronbach's $\alpha:$ : 0.811) } \\
\hline g Remind them when they have used it for too long or too late & 0.825 \\
\hline \multicolumn{2}{|l|}{ Close Monitoring(Cronbach's $\alpha: 0.850)$} \\
\hline k. Install software to filter access & 0.686 \\
\hline 1 Set rules about which websites can be visited. & 0.828 \\
\hline $\mathrm{m}$ Set rules about downloading and uploading material. & 0.807 \\
\hline $\mathrm{n}$ Set rules about disclosure of personal information. & 0.610 \\
\hline o Monitoring the web activities and online communication of children & 0.764 \\
\hline
\end{tabular}

17). Only $3.3 \%$ indicated that they were not confident at all. Confidence levels for these two aspects were significantly correlated (Table 5).

Table 6 shows information about the independent variables contributing to the two dependent variables in the multiple regression models. There are three broad categories of variables, namely, 1) Parents' and children's profile, 2) Internet parenting, and 3) Family relationship. Hierarchical multiple regression models involving these three broad categories in three sub-models were tested. The first submodel included variables relating to parents' and children's profile. The second sub-model included both the first and second broad categories of variables (Internet parenting), and the third sub-model included all three categories of variables. A stepwise method of entry was adopted in the regression models.

Before testing the regression models, correlations of each independent variable with the dependent variables were examined. Table 7 shows the results. Only variables with significant correlations with the respective dependent variable were included in constructing the multiple regression models.

Table 8 presents the result of the hierarchical regression model for the first dependent variable and the three broad categories of independent variables. In the first sub-model that included only the parents' and children's profile, four variables retained in the first sub-model. The adjusted $R^{2}$ for the first sub-model was 0.126. Parents' Internet knowledge, higher level of educational attainment, having a younger child and child using more time in the Internet were all associated with a higher confidence level in helping children benefit from using the Internet. In the second sub-model, a total of nine variables related to Internet parenting were entered. Four variables remained and the cumulative adjusted $R^{2}$ was 0.197 . Adopting an authoritative parenting style and using involvement as a supervision method were positively correlated with the dependent variable. Using close monitoring to supervise and holding an attitude that the Internet is filled with undesirable information had a negative association. Of the four variables in the first sub-model, child's time in using the Internet did not remain in the second sub-model. In the final sub-model, the final category of variables (family relationship, six variables) was added. Two variables, family cohesion and parent-child relationship were positively associated with the dependent variable. In the final sub-model, all independent variables except child's time in using the Internet in the previous sub-models were retained. The final cumulative adjusted $R^{2}$ was $0.240, F(10$, $1432)=46.252, p<0.001$.

Similar results were found in the second dependent variable, namely, parents' confidence in protecting children from possible Internet threats. The adjusted $R^{2}$ for the model was $0.155, F(8,1586)=37.661, p<0.001$. Of all the independent variables that showed significant bivariate correlations entered into multiple regression, eight remained in the final model. Parents' internet knowledge, adopting authoritative parenting style and close monitoring, family cohesion and satisfactory parent-child relationship were positively correlated with the dependent variable. On the

contrary, age of child, using permissive supervision and holding the attitude that the Internet is filled with undesirable 
Table 3. Factors of parenting style.

\begin{tabular}{|c|c|c|}
\hline \multicolumn{3}{|c|}{ Authoritative (8 items, Cronbach's $\alpha$ : 0.854) } \\
\hline $\mathrm{d}$ & I explain to our child how we feel about the child's good and bad choices and actions. & 0.719 \\
\hline g & I encourage our child to freely express himself/herself even when disagreeing with parents. & 0.698 \\
\hline $\mathrm{a}$ & I am responsive to our child's feelings and needs & 0.629 \\
\hline $\mathrm{q}$ & I show respect for our child's opinions by encouraging our child to express them. & 0.616 \\
\hline $\mathrm{j}$ & I give comfort and understanding when our child is upset. & 0.608 \\
\hline \multicolumn{3}{|c|}{ Authoritarian (Irritable) (9 items, Cronbach's $\alpha: 0.799$ ) } \\
\hline $\mathrm{y}$ & I scold and criticize when our child's behavior doesn't meet our expectations. & 0.616 \\
\hline $\mathrm{n}$ & I explode in anger towards our child & 0.604 \\
\hline $\mathrm{f}$ & I find it difficult to discipline our child & 0.582 \\
\hline $\mathrm{x}$ & I terminate financial support as a means to punish our child. & 0.485 \\
\hline $\mathrm{p}$ & I grab our child when I don't like what he/she does & 0.443 \\
\hline $\mathrm{v}$ & I do not give our child reasons when I threat to punish our child. & 0.430 \\
\hline \multicolumn{3}{|c|}{ Authoritarian (Controlling) (4 items, Cronbach's $\alpha: 0.707$ ) } \\
\hline & I remind our child of all I have done for him/her. & 0.731 \\
\hline
\end{tabular}

Table 4. Satisfaction with various family aspects.

\begin{tabular}{|c|c|c|c|c|c|c|c|c|c|c|}
\hline \multirow[b]{2}{*}{ Satisfied and Very Satisfied } & \multicolumn{4}{|c|}{ Education Attainment of Parents $(N=1595)$} & \multicolumn{4}{|c|}{ Gender of Parent $(N=1595)$} & \multirow{2}{*}{\multicolumn{2}{|c|}{$\begin{array}{c}\text { Total } \\
(N=\mathbf{1 5 9 5})\end{array}$}} \\
\hline & \multicolumn{2}{|c|}{$\begin{array}{l}\text { Junior Secondary or } \\
\text { Below }(\mathbf{n}=502)\end{array}$} & \multicolumn{2}{|c|}{$\begin{array}{l}\text { Senior Secondary or } \\
\text { Above }(n=1093)\end{array}$} & \multicolumn{2}{|c|}{ Male $(n=720)$} & \multicolumn{2}{|c|}{ Female $(n=875)$} & & \\
\hline a. Time spent with children & 418 & 83.3 & 928 & 84.9 & 605 & 84.0 & 741 & 84.8 & 1346 & 84.4 \\
\hline b. Parent-child relationship & 462 & 92.0 & 1045 & 95.6 & 671 & 93.2 & 836 & 95.5 & 1507 & 94.5 \\
\hline e. Communication among family members & 438 & 87.3 & 992 & 90.8 & 625 & 86.8 & 805 & 92.0 & 1430 & 89.7 \\
\hline f. Family cohesion & 445 & 88.6 & 1044 & 95.5 & 665 & 92.4 & 823 & 94.1 & 1489 & 93.4 \\
\hline
\end{tabular}

information were negatively associated with the dependent variable (Table 9).

\section{DISCUSSION AND IMPLICATIONS}

In this study, our weighted sample represented Shanghai households with children aged 9-17. Nearly one-third of the 
Table 5. Confidence levels of parents in helping their children.

\begin{tabular}{|c|c|c|c|c|}
\hline & \multicolumn{4}{|c|}{ Confidence of Parents in } \\
\hline & \multicolumn{2}{|c|}{ Helping Children Benefit from the Use of the Internet } & \multicolumn{2}{|c|}{ Protecting Children from Possible Internet Threat } \\
\hline & $n$ & $\%$ & $n$ & $\%$ \\
\hline Not confident at all & 127 & 8.0 & 53 & 3.3 \\
\hline A little confident & 227 & 14.2 & 171 & 10.7 \\
\hline Somewhat confident & 564 & 35.4 & 517 & 32.4 \\
\hline Confident & 621 & 38.9 & 775 & 48.6 \\
\hline Highly confident & 56 & 3.5 & 79 & 5.0 \\
\hline Total & 1595 & 100.0 & 1595 & 100.0 \\
\hline Mean (Range $=1-5)$ & \multicolumn{2}{|c|}{3.16} & \multicolumn{2}{|c|}{3.41} \\
\hline Standard deviation (SD) & \multicolumn{2}{|c|}{0.983} & \multicolumn{2}{|c|}{0.869} \\
\hline Pearson's correlation coefficient & \multicolumn{4}{|c|}{$r(1595)=0.541, p<0.001$} \\
\hline
\end{tabular}

Table 6. Initial factors to be included in the regression model.

\begin{tabular}{|c|c|c|c|c|}
\hline & Range of Scores & Mean & SD & Valid Cases \\
\hline \multicolumn{5}{|l|}{ Parents' and Children's Background } \\
\hline Internet knowledge of parent & $1-4(1=$ Not at all $)$ & 2.64 & 1.03 & 1595 \\
\hline Gender of parent & $1,2(1=$ Male; $2=$ Female $)$ & 1.55 & 0.50 & 1595 \\
\hline Age of parent & & 42.40 & 8.69 & 1595 \\
\hline Education of parent & $1,2(1 \leqq$ Junior Sec.; $2 \geqq$ Senior Sec. $)$ & 1.69 & 0.47 & 1595 \\
\hline Agricultural household & $0,1(0=\mathrm{No} ; 1=\mathrm{Yes})$ & 0.20 & 0.40 & 1595 \\
\hline Age of child (9-17) & $9-17$ & 12.62 & 2.69 & 1595 \\
\hline Gender of child & $1,2$ (1=Male; $2=$ Female $)$ & 1.51 & 0.50 & 1595 \\
\hline Child's time using Internet & 1-5 (1=Too little, $5=$ Too much $)$ & 2.73 & .070 & 1433 \\
\hline \multicolumn{5}{|l|}{ Internet Parenting } \\
\hline \multicolumn{5}{|l|}{ Methods to supervise and guide children in using Internet } \\
\hline Involvement & 1-5 (From never to always) & 2.35 & 0.72 & 1595 \\
\hline Restriction & 1-5 (From never to always) & 3.37 & 0.91 & 1595 \\
\hline Monitoring & 1-5 (From never to always) & 2.41 & 1.00 & 1595 \\
\hline \multicolumn{5}{|l|}{ Parenting style } \\
\hline Authoritative & 1-5 (From low to high) & 3.46 & 0.55 & 1595 \\
\hline Authoritarian (Irritable) & $1-5$ (From low to high) & 2.57 & 0.58 & 1595 \\
\hline Authoritarian (Controlling) & 1-5 (From low to high) & 2.88 & 0.72 & 1595 \\
\hline Permissive & $1-5$ (From low to high) & 2.06 & 0.75 & 1595 \\
\hline \multicolumn{5}{|l|}{ Parent's attitude towards Internet } \\
\hline The Internet is indispensable in modern life. & \multirow{6}{*}{$\begin{array}{l}1-5(1=\text { Strongly disagree; } 5=\text { Strongly } \\
\text { agree })\end{array}$} & 3.73 & 0.91 & 1595 \\
\hline Incapacity to use the Internet will lead to disconnection from society. & & 3.61 & 0.93 & 1595 \\
\hline The Internet helps learning new things. & & 3.91 & 0.76 & 1595 \\
\hline It is easy to obtain information from the Internet. & & 3.94 & 0.75 & 1595 \\
\hline It is easy to get indulged in the use of the Internet. & & 3.39 & 0.91 & 1595 \\
\hline The Internet is filled with undesirable information. & & 3.32 & 0.92 & 1595 \\
\hline \multicolumn{5}{|l|}{ Family relationship } \\
\hline Time spent with children & \multirow{6}{*}{$1-5(1=$ Very unsatisfied; $5=$ Very satisfied $)$} & 3.92 & 0.72 & 1595 \\
\hline Parent-child relationship & & 4.12 & 0.52 & 1595 \\
\hline Time spent with family members & & 3.94 & 0.69 & 1595 \\
\hline Family atmosphere & & 4.10 & 0.55 & 1595 \\
\hline Communication among family members & & 4.01 & 0.61 & 1595 \\
\hline Family cohesion & & 4.12 & 0.54 & 1595 \\
\hline
\end{tabular}

parents had education attainment of junior secondary or lower. Among these parents, more than one in five had never used a computer. Compared with the better-educated parents, only one in twenty had not used a computer before. Our study shows that parental knowledge of computer and
Internet use had a predominant effect on parents' confidence in supervising and guiding their children in using the Internet.

In this age of fast technological advancement, parents have to struggle hard on one hand, to keep up with the 
Table 7. Correlations of initial factors with the dependent variables.

\begin{tabular}{|c|c|c|c|c|}
\hline \multirow[b]{2}{*}{ Parents' and Children's Background } & \multicolumn{2}{|c|}{ Benefit them from Use of Internet } & \multicolumn{2}{|c|}{ Protect them from Threats } \\
\hline & $r$ & $d f$ & $r$ & $d f$ \\
\hline Internet knowledge of parent & $0.329^{* *}$ & 1595 & $0.196^{* *}$ & 1595 \\
\hline Gender of parent & 0.031 & 1595 & 0.043 & 1595 \\
\hline Age of parent & $-0.084^{* *}$ & 1595 & $-0.089^{* *}$ & 1595 \\
\hline Education of parent & $0.249^{* *}$ & 1595 & $0.119^{* *}$ & 1595 \\
\hline Agricultural household & $-0.060^{*}$ & 1595 & 0.006 & 1595 \\
\hline Age of child (9-17) & $-0.099^{* *}$ & 1595 & $-0.122^{* *}$ & 1595 \\
\hline Gender of child (1=Male, $2=$ Female) & 0.003 & 1595 & 0.030 & 1595 \\
\hline Child's time using Internet (1-5, $1=$ Too little $)$ & $0.054^{*}$ & 1433 & 0.031 & 1433 \\
\hline \multicolumn{5}{|l|}{ Internet parenting } \\
\hline \multicolumn{5}{|l|}{ Methods to supervise and guide children in using Internet } \\
\hline Involvement & $0.352^{* *}$ & 1595 & $0.159^{* *}$ & 1595 \\
\hline Restriction & $0.120^{* *}$ & 1595 & $0.136^{* *}$ & 1595 \\
\hline Monitoring & $0.136^{* *}$ & 1595 & $0.178^{* *}$ & 1595 \\
\hline \multicolumn{5}{|l|}{ Parenting style } \\
\hline Authoritative & $0.281^{* *}$ & 1595 & $0.257^{* *}$ & 1595 \\
\hline Authoritarian (Irritable) & 0.005 & 1595 & -0.032 & 1595 \\
\hline Authoritarian (Controlling) & 0.036 & 1595 & $0.063^{*}$ & 1595 \\
\hline Permissive & -0.008 & 1595 & $-0.084^{* *}$ & 1595 \\
\hline \multicolumn{5}{|l|}{ Parent's attitude towards Internet } \\
\hline The Internet is indispensable in modern life. & $0.158^{* *}$ & 1595 & 0.041 & 1595 \\
\hline Incapacity to use the Internet will lead to disconnection from society. & $0.116^{* *}$ & 1595 & $0.053^{* *}$ & 1595 \\
\hline The Internet helps learning new things. & $0.092^{* *}$ & 1595 & -0.021 & 1595 \\
\hline It is easy to obtain information from the Internet. & $0.096^{* *}$ & 1595 & 0.021 & 1595 \\
\hline It is easy to get indulged in the use of the Internet. & -0.025 & 1595 & $-0.067^{* *}$ & 1595 \\
\hline The Internet is filled with undesirable information. & $-0.132^{* *}$ & 1595 & $-0.088^{* *}$ & 1595 \\
\hline \multicolumn{5}{|l|}{ Family relationship } \\
\hline Time spent with children & $0.100^{* *}$ & 1595 & $0.074^{* *}$ & 1595 \\
\hline Parent-child relationship & $0.216^{* *}$ & 1595 & $0.228^{* *}$ & 1595 \\
\hline Time spent with family members & $0.107^{* *}$ & 1595 & $0.114^{* *}$ & 1595 \\
\hline Family atmosphere & $0.238^{* *}$ & 1595 & $0.225^{* *}$ & 1595 \\
\hline Communication among family members & $0.173^{* *}$ & 1595 & $0.172^{* *}$ & 1595 \\
\hline Family cohesion & $0.259^{* *}$ & 1595 & $0.265^{* *}$ & 1595 \\
\hline
\end{tabular}

Note: $r$ refers to Pearson's correlation coefficient; $d f$ refers to degrees of freedom; ** Correlations at 0.01 level.

technological changes, and to work out the new parenting methods in supervising and guiding their children in negotiating with the new technological world on the other. In this study, about one-fifth of the parents had limited confidence in helping their children benefit from the use of the Internet, and one-eighth of them were so in protecting their children from the risks of harmful effect in using the
Internet. Only about half of them expressed that they had such confidence.

The two variables of parenting confidence were taken as dependent variables and multiple regression models were used to test the association between the three broad categories of independent variables (i.e. parents' and children's profile, Internet parenting, and family 
Table 8. Hierarchical multiple regression model for explaining parents' confidence in helping children benefit from the use of the internet.

\begin{tabular}{|c|c|c|c|c|c|c|c|c|c|}
\hline & \multicolumn{3}{|c|}{ Sub-Model 1} & \multicolumn{3}{|c|}{ Sub-Model 2} & \multicolumn{3}{|c|}{ Sub-Model 3 (final model) } \\
\hline & $\mathbf{B} / \mathbf{S E}$ & Beta & $t$ & $\mathbf{B} / \mathbf{S E}$ & Beta & $t$ & $\mathbf{B} / \mathbf{S E}$ & Beta & $t$ \\
\hline \multicolumn{10}{|l|}{ Parents' and children's background } \\
\hline Internet knowledge of parent & $0.250 / 0.026$ & 0.262 & $9.493^{* * *}$ & $0.138 / 0.028$ & 0.144 & $4.891^{* * *}$ & $0.149 / 0.027$ & 0.155 & $5.416^{* * *}$ \\
\hline Education of parent & $0.284 / 0.058$ & 0.134 & $4.918^{* * *}$ & $0.177 / 0.056$ & 0.084 & $3.142^{* *}$ & $0.153 / 0.055$ & 0.072 & $2.775^{* *}$ \\
\hline Age of child (9-17) & $-0.021 / 0.009$ & -0.057 & $-2.280^{*}$ & $-0.025 / 0.009$ & -0.068 & $-2.757^{* *}$ & $-0.025 / 0.009$ & -0.068 & $-2.834^{* *}$ \\
\hline Child's time using Internet & $0.080 / 0.035$ & 0.056 & $2.258^{*}$ & $0.041 / 0.034$ & 0.029 & 1.205 & $0.047 / 0.034$ & 0.033 & 1.397 \\
\hline \multicolumn{10}{|c|}{ Sub-model 1: Cumulative $R^{2}=0.128$, Cumulative $R_{\text {adj }}^{2}=0.126$} \\
\hline \multicolumn{10}{|l|}{ Internet parenting } \\
\hline Involvement & & & & $0.291 / 0.042$ & 0.213 & $6.968^{* * *}$ & $0.284 / 0.041$ & 0.208 & $7.010^{* * *}$ \\
\hline Close Monitoring & & & & $-0.055 / 0.026$ & -0.057 & $-2.088^{*}$ & $-0.064 / 0.026$ & -0.065 & $-2.463^{*}$ \\
\hline Authoritative & & & & $0.306 / 0.046$ & 0.172 & $6.719^{* * *}$ & $0.207 / 0.046$ & 0.116 & $4.527^{* * *}$ \\
\hline The Internet is filled with undesirable information. & & & & $-0.073 / 0.027$ & -0.068 & $-2.817^{* *}$ & $-0.089 / 0.025$ & -0.083 & $-3.498^{* * *}$ \\
\hline \multicolumn{10}{|c|}{ Sub-model 2: Cumulative $R^{2}=0.201$, Cumulative $R_{\text {adj }}^{2}=0.197$} \\
\hline \multicolumn{10}{|l|}{ Family relationship } \\
\hline Family cohesion & & & & & & & $0.285 / 0.052$ & 0.156 & $5.494^{* * *}$ \\
\hline Parent-child relationship & & & & & & & $0.167 / 0.054$ & 0.089 & $3.097^{* *}$ \\
\hline
\end{tabular}

relationship) and the dependent variables. The results identified that in addition to parental Internet knowledge, an authoritative parenting style, better parent-child relationship and family cohesion were positively associated with parenting confidence in internet supervision. On the other hand, holding a negative attitude towards the Internet showed a negative association with parenting confidence. Results also revealed that parents with older children showed lower confidence levels in internet supervision.

With the limitation of cross-sectional study, we were not able to establish causal relationships among the variables. However, the multiple regression models provided insights that besides increasing parents' internet knowledge, it is also important to help parents learn authoritative parenting and reflect on their attitude towards the Internet. Our study shows that the parenting method of restriction was most frequently adopted by Shanghai parents in internet supervision. The findings suggest it will be beneficial to assist parents effectively use involvement in supervising children's internet use. This is particularly so for parents on the lower socio-economic strata. These parents are likely to have limited knowledge in using the new technology and access to programmes that address their new parenting needs. This renders parents' lack of competence in assisting their children to make full use of the Internet. Moreover, the restriction imposed by parents in children's playing internet games and other online entertainments further creates parentchild conflicts and tensions.
Internet is the most powerful learning and communicating technology human has ever created, but it is equally powerful to distract the attention of the children away from formal school learning and other daily social activities. The role of parents, teachers, and other social service professionals are very important in helping children to make good use of the Internet to benefit their personal development. In addition, social work practitioners are in a good position to identify the parents in needs and provide support to them to enhance their capabilities in performing their parenting functions in the fast changing technological environment.

\section{CONFLICT OF INTEREST}

The authors confirm that this article content has no conflict of interest.

\section{ACKNOWLEDGEMENTS}

This paper is the output of a GRF project entitled "Digital divide challenges among children in low-income families - the case of Shanghai" funded by the University Grant Council, Hong Kong (Ref No: 754912).

\section{DISCLOSURE}

Part of this article has been previously published in Journal of Technology in Human Services Volume 28, Issue 
Table 9. Hierarchical multiple regression model for explaining parents' confidence in protecting children from possible internet threats.

\begin{tabular}{|c|c|c|c|c|c|c|c|c|c|}
\hline & \multicolumn{3}{|c|}{ Sub-Model 1} & \multicolumn{3}{|c|}{ Sub-Model 2} & \multicolumn{3}{|c|}{ Sub-Model 3 (Final Model) } \\
\hline & $\mathbf{B} / \mathbf{S E}$ & Beta & $t$ & $\mathbf{B} / \mathbf{S E}$ & Beta & $t$ & $\mathbf{B} / \mathbf{S E}$ & Beta & $t$ \\
\hline \multicolumn{10}{|l|}{ Parents' and children's background } \\
\hline Internet knowledge of parent & $0.154 / 0.021$ & 0.182 & $7.367^{* * *}$ & $0.092 / 0.021$ & 0.109 & $4.311^{* * *}$ & $0.097 / 0.021$ & 0.115 & $4.690^{* * *}$ \\
\hline Age of child (9-17) & $-0.031 / 0.008$ & -0.096 & $-3.876^{* * *}$ & $-0.025 / 0.008$ & -0.078 & $-3.247^{* *}$ & $-0.025 / 0.008$ & -0.078 & $-3.308^{* *}$ \\
\hline \multicolumn{10}{|c|}{ Sub-model 1: Cumulative $R^{2}=0.047$, Cumulative $R_{\text {adj }}^{2}=0.046$} \\
\hline \multicolumn{10}{|l|}{ Internet parenting } \\
\hline Close monitoring & & & & $0.087 / 0.022$ & 0.101 & $3.970^{* * *}$ & $0.075 / 0.021$ & 0.087 & $3.810^{* *}$ \\
\hline Authoritative & & & & $0.309 / 0.039$ & 0.196 & $7.897^{* * *}$ & $0.220 / 0.039$ & 0.139 & $5.568^{* * *}$ \\
\hline Permissive & & & & $-0.095 / 0.028$ & -0.082 & $-3.394^{* *}$ & $-0.076 / 0.027$ & -0.066 & $-2.779^{* *}$ \\
\hline The Internet is filled with undesirable information. & & & & $-0.059 / 0.023$ & -0.062 & $-2.570^{*}$ & $-0.071 / 0.022$ & -0.075 & $-3.200^{* *}$ \\
\hline \multicolumn{10}{|c|}{ Sub-model 2: Cumulative $R^{2}=0.112$, Cumulative $R_{\text {adj }}^{2}=0.108$} \\
\hline \multicolumn{10}{|l|}{ Family relationship } \\
\hline Family cohesion & & & & & & & $0.262 / 0.046$ & .0163 & $5.757^{* * *}$ \\
\hline Parent-child relationship & & & & & & & $0.154 / 0.048$ & 0.092 & $3.230^{* *}$ \\
\hline
\end{tabular}

4, pages 252-273 and Volume 33, Issue 1, 2015, pages 5371 .

\section{REFERENCES}

[1] China Internet Network Information Center. The $33^{\text {rd }}$ statistical report on Internet development in China 2014. [accessed 18 Sep 2014]. Available from: http://www1.cnnic.cn/IDR/ReportDownloa ds/201404/U020140417607531610855.pdf.

[2] Young KS. Internet addiction: a new clinical phenomenon and its consequences. Am Behav Sci 2004; 48(4): 402-15.

[3] Dombrowski SC, Gischlar KL, Durst T. Safeguarding young people from cyber pornography and cyber sexual predation: a major dilemma of the Internet. Child Abuse Rev 2007; 16(3): 15370.

[4] Whelan DL. Parents: internet is a double-edged sword. Sch Lib J 2006; 52(7): 15

[5] Lei J, Zhou J. Digital divide: how do home Internet access and parental support affect student outcomes? Educ Sci 2012; 2: 45-53.

[6] van den Eijnden RJJM, Spijkerman R, Vermulst AA, van Rooij TJ, Engels RCME. Compulsive Internet use among adolescents: bidirectional parent-child relationships. J Abnorm Child Psych 2010; 38(1): 77-89.

[7] Lou S-J, Shin R-C, Liu H-T, Guo Y-C, Tseng K-H. The influence of the sixth graders' parents' Internet literacy and parenting style on Internet parenting. Turk Online J Educ Tech 2010; 9(4): 173-84.

[8] Wang R, Bianchi SM, Raley SB. Teenagers' Internet use and family rules: a research note. J Marriage Fam 2005; 67(5): 124958.

[9] Eastin MS, Greenberg BS, Hofschire L. Parenting the internet. J Commun 2006; 56: 486-504.

[10] Beebe TJ, Asche SE, Harrison PA, Quinlan KB. Heightened vulnerability and increased risk-taking among adolescent chat room users: Results from a statewide school survey. J Adolescent Health 2004; 35(2): 116-23.

[11] Mitchell KJ, Finkelhor D, Janis W. Protecting youth online: family use of filtering and blocking software. Child Abuse Negl 2005; 29: 753-65.

[12] European Comission. Towards a safer use of the Internet for children in the EU: A parents' perspective 2008.
[13] Valentine G, Holloway S. On-line Dangers?: Geographies of parents' fears for children's safety in cyberspace. Prof Geogr 2001; 53(1): 71-83

[14] Valcke M, Bonte S, De Wever B, Rots I. Internet parenting styles and the impact on Internet use of primary school children. Comput Educ 2010; 55: 454-64.

[15] Lee S-J, Chae Y-G. Children's Internet use in a family context: Influence on family relationships and parental mediation. Cyber Psychol Behav 2007; 10(5): 640-4.

[16] Baumrind D. The influence of parenting style on adolescent competence and substance use. J Early Adolesc 1991; 11(1): 56-95.

[17] McKinney C, Renk K. Multivariate models of parent-late adolescent gender dyads: The importance of parenting processes in predicting adjustment. Child Psychiatry Hum Dev 2008 Jun; 39(2): 140-70.

[18] Cohen DA, Rice J. Parenting styles, adolescent substance use, and academic achievement. J Drug Educ 1997; 27(2): 199-211.

[19] Heaven PC, Ciarrochi J. Parental styles, conscientiousness, and academic performance in high school: a three-wave longitudinal study. Pers Soc Psychol B 2008; 34(4): 451-61.

[20] Steinberg L, Lamborn SD, Dornbusch SM, Darling N. Impact of parenting practices on adolescent achievement: authoritative parenting, school involvement, and encouragement to succeed. Child Dev 1992; 63(5): 1266-81.

[21] Buri JR, Louiselle PA, Misukanis TA, Mueller RA. Effects of parental authoritarianism and authoritativeness on self-esteem. Pers Soc Psychol B 1988; 14(2): 271-82.

[22] Masayo U, Ayuko S, Keiichiro A, Toshinori K. The impact of authoritative, authoritarian, and permissive parenting styles on children's later mental health in Japan: Focusing on parent and child gender. J Child Fam Stud 2014; 23(2): 293-302.

[23] Leung K, Lau S, Lam W-L. Parenting styles and academic achievement: A cross cultural study. Merrill Palmer Quart 1998; 44(2): 157-72.

[24] Aunola K, Stattin H, Nurmi J-E. Parenting styles and adolescents' achievement strategies. J Adolesc 2000; 23: 205-22.

[25] Ang RP. Effects of parenting style on personal and social variables for Asian adolescents. Am J Orthpsychiatry 2006; 76(4): 503-11.

[26] Ramsey A, Watson PJ, Biderman MD. Self-reported narcissism and perceived parental permissiveness and authoritarianism. J Genet Psychol 1996; 157(2): 227-38. 
[27] Elias H, Yee TH. Relationship between perceived paternal and maternal parenting styles and student academic achievement in selected secondary schools. Eur J Soc Sci 2009; 9: 181-92.

[28] Crncec R, Barnett B, Matthey S. Review of scales of parenting confidence. J Nurs Measurement 2010; 18(3): 210-40.

[29] Coleman PK, Karraker KH. Self-efficacy and parenting quality: Findings and future applications. Dev Rev 1997; 18: 47-85.

[30] Jones TL, Prinz RJ. Potential roles of parental self-efficacy in parent and child adjustment: A review. Clin Psychol Rev 2005; 25: 341-63.
[31] Wong YC. Cyber-parenting: Internet benefits, risks and parenting issues. J Technol Hum Serv 2010; 28(4): 252-73.

[32] McKay M. Parenting practices in emerging adulthood: Development of a new mesaure. MS thesis, Brigham Young University 2006 .

[33] Robinson CC, Porter CL, Hart CH. A multi-informant approach for studing parenting styles: linking self and spousal reports to child outcomes. Poster presented at Inernational Society for the Study of Behavioral Development. Ghent: Belgium 2004.

(C) Wong et al.; Licensee Bentham Open.

This is an open access article licensed under the terms of the Creative Commons Attribution Non-Commercial License (http://creativecommons.org/licenses/by-nc/3.0/) which permits unrestricted, non-commercial use, distribution and reproduction in any medium, provided the work is properly cited. 